\title{
Consumer-oriented evaluation of the service provided by the department of health education and information in Alexandria, Egypt
}

\author{
Original \\ Article \\ Abdel-Kader', Azza A. Abou-Zeid ${ }^{3}$ \\ ${ }^{1}$ Health Education and Behavior Sciences, ${ }^{2}$ Hospital Administration, Department of Health \\ Administration and Behavior Sciences, High Institute of Public Health, Alexandria University, \\ Alexandria, Egypt \\ ${ }^{3}$ Training Administration, Alexandria Health Directorate, Ministry of Health, Alexandria, \\ Egypt
}

Mona S. Wahba ${ }^{1}$, Ensaf S. Abdel-Gawwad ${ }^{1}$,Mohamed D. El-Bourgy ${ }^{1}$ Hoda Z.

\begin{abstract}
Background: Assessing consumers' satisfaction with health education services can help in monitoring the quality of provided service and understanding consumers' perceptions and utilization patterns of the service.

Materials and Methods: A cross-sectional descriptive study targeting consumers attending the health education sessions provided by Alexandria Department of Health Education and Information (DHEI) at different governmental health facilities and nongovernmental organizations was performed. A simple random sample of 400 participants was interviewed using an interview questionnaire assessing respondents' socioeconomic characteristics, health literacy, attitude toward health education services, and satisfaction with the health education service provided by the DHEI..

Results: Approximately $70 \%$ of the consumers' sample showed fair health literacy level. Most of the sample mentioned physicians a credible source of health knowledge followed by $58.8 \%$ who selected health education sessions as another trusted health information source. Overall, $90 \%$ of the sample was highly satisfied by the service overall. Behavior and skills of the service providers were the most satisfying aspects, whereas health education materials obtained the least satisfaction. Consumers' educational level and healthcare affordability proved to have a significant positive influence on their satisfaction $(\beta=0.307$ and 0.191 , respectively) whereas occupation and family income showed a significant negative influence $(P<0.001)$.

Conclusion: The service provided by Alexandria DHEI is highly satisfying to its target audience mainly in terms of providers and accessibility. Enhancing the technical skills of the department staff through training is highly recommended. The department is also recommended to advocate for the credibility of social workers and health visitors as health educators among the community.
\end{abstract}

Received: 06 March 2017, Accepted: 24 Janurary 2018

Key Words: Consumers, consumer orientation, health education service, health information, health literacy, satisfaction

Corresponding Author: Mona S. Wahba, Ph.D., Department of Health Administration and Behavior Sciences, High Institute of Public Health, Alexandria University, Alexandria, Egypt, Tel.: +20 100526 6391, E-mail: monasalemwahba@ hotmail.com

ISSN: 0013-2446, Vol. 92, No.2

\section{INTRODUCTION}

The health market has markedly shifted toward consumer orientation and patient centeredness ${ }^{[1]}$. Social marketing which is central to health education bears consumer orientation as a fundamental pillar to carry on its strategies ${ }^{[2]}$. One critical dimension for evaluating health services is the appraisal from consumers' point of view. Consumers' satisfaction refers to the overall consumer attitude toward the service and its provider, with an emotional reaction to the difference between what consumers anticipate and what they receive, regarding the fulfillment of some needs, goals, or desire ${ }^{[3,4]}$. Assessing consumer satisfaction with the service they receive provides a rich database for different stakeholders to monitor the quality of provided service and understand consumers' perceptions and utilization patterns of the service ${ }^{[5,6]}$.

Various determinants were deemed to predict degree of consumers' satisfaction. Consumer characteristics such as demographic factors, socioeconomic status, and general health status are among such predictors. Attributes related to the service include the way the service is delivered, the setting in which it is provided, as well as characteristics and experience of the provider ${ }^{[7,8]}$. Consumer satisfaction measuring tools should incorporate dimensions of technical, 
interpersonal, social, and moral aspects of the service. The correlation between demographic factors such as age, sex, health status, and level of education with consumer satisfaction can also be established in different research tools. Although service providers cannot practically tackle nonmodifiable factors influencing satisfaction, such as demographics, understanding such correlation can help readjust the service provision to adapt more to consumers' background ${ }^{[9]}$.

In health education, like any other health service, consumer satisfaction is an indispensable tool for service evaluation and quality improvement. In health education, cultural sensitivity of the provider and the interventions, on top of other provider-related factors like credibility and communication proved to have the upper hand in determining audience satisfaction ${ }^{[10]}$. The Department of Health Education and Information (DHEI) affiliated to the Directorate of Health Affairs principally targets individuals seeking different health services at various governmental health settings upon which the DHEI staff members are distributed. The department services also target audience at different community settings and civil organizations in addition to outreach activities and campaigns. The present study aimed at assessing consumers' perspectives and satisfaction about the health education services provided by the DHEI.

\section{MATERIALS AND METHODS}

\section{Study design and settings}

A cross-sectional descriptive study design was used. The study targeted audience receiving health education services provided by Alexandria DHEI at different governmental health facilities and nongovernmental organizations.

\section{Sampling}

To detect the level of satisfaction among consumers of the health education services provided by the DHEI, a minimal sample size of 384 consumers was calculated based on an assumption of satisfaction $=50 \%$, precision of $5 \%$, and $\alpha=0.05$. A random sample rounded to 400 consumers (attendants of different health education sessions, regardless of the session's topic, type or content) was selected for the study. Of the eight health districts in Alexandria, three districts were selected on the basis of having the highest population densities in Alexandria Governorate. Using stratified random sampling techniques, 10 peripheral units including primary health centers, hospitals, and civil organizations were selected from each district. All consumers attending health education sessions provided by the DHEI at the preselected settings were invited to participate in the study, and those who verbally consented to participate were enrolled until the entire sample size was fulfilled. The selected civil organizations were visited only once to avoid re-enrollment of the same subjects receiving different social services at the organization at different times. The selected preventive and curative facilities were revisited till the whole sample size of consumers was fulfilled.

\section{Data collection methods}

Data was collected through face-to-face interviews during the period from April 2015 to June 2015 using a precoded interview questionnaire. The questionnaire was developed after reviewing a number of references concerning socioeconomic standard measurement ${ }^{[11]}$, health literacy measurement ${ }^{[12,13]}$ and consumer satisfaction ${ }^{[14,15]}$. The audience of DHEI educational sessions was interviewed in the setting after attending the health education session.

The questionnaire is composed of four sections. The first section involved the sociodemographic profile of the study participants. Updated Fahmy and El-Sherbini socioeconomic scoring system ${ }^{[11]}$ was used to categorize the socioeconomic level of participants. The used scale included data about education and occupation of the respondent and spouse, family members, home sanitation, possessions, economic status, healthcare, and source of health information. Scores of different socioeconomic domains were summed up with a maximum total score of ' 84 '. Socioeconomic level was classified into very low $(<25 \%)$, low $(25 \%$ to $<50 \%)$, middle $(50 \%$ to $<75 \%)$, and high $(75 \%+)$ levels.

The second section of the questionnaire aimed at measuring the general health literacy of the consumers through combining the Single Item Literacy Scale (SILS) ${ }^{[12]}$ and relevant items of Medication Understanding and Use Self-Efficacy ${ }^{[13]}$ instruments. The first item in the used scale was the SILS question, 'how often the respondent needs someone's help to understand health instructions'. Other items assessed the ability of the respondent to obtain, understand, and apply health information. The SILS question had three response options, which were scored as follows: 'always $=0$ ', 'sometimes $=1$ ', and 'never $=2$ '. Other health literacy items were scored on a three-point rating scale with response options from 'never' to 'always', scored from ' 0 to 2 '. Literacy level was calculated as a percentage of the maximum total score of ' 20 ' and categorized as 'high' if exceeding $80 \%$ of the total score and 'poor' if below $60 \%$.

The attitude of consumers toward health education services was assessed in the third section through a fivepoint Likert scale, option ranging from 'strongly disagree' to 'strongly agree'. Attitude items were scored from ' 0 to 4 ', where ' 0 ' indicated strong disagreement with health education services and ' 4 ' signified the strong agreeing position. Maximum total attitude score was ' 32 '. Overall attitude was considered 'positive' if total score exceeded $66.6 \%$ of the total, 'neutral' if score ranged between 33.3 and $66.6 \%$, and 'negative' if lower than $33.3 \%$.

The fourth section examined the satisfaction of consumers with six domains of the provided service: 
(i) effectiveness of the service in raising awareness and modifying behavior, (ii) behavior and skills of the DHEI health educators, (iii) the appropriateness and quality of the used teaching methods, (iv) the quality of the provided educational materials, (v) accessibility to the provided health education activities, and (vi) the overall satisfaction with the service. Consumers' satisfaction with different items was assessed on a five-point Likert-like scale ranging from 'very satisfied' to 'very dissatisfied'. The response of each statement was scored from ' 0 to 4' with higher score denoting higher satisfaction. This section included 40 items with a maximum total score of 160 . Consumers' satisfaction was deemed 'high' if total score exceeded $66.6 \%$ whereas poor satisfaction was considered if satisfaction scores were below $33.3 \%$.

\section{Statistical analysis}

Collected data was revised, coded, and fed to statistical package for the social sciences, version 21 (SPSS; SPSS Inc., Chicago, Illinois, USA). Multiple linear regression was used to examine the socioeconomic determinants of consumers' overall satisfaction. Five variables were entered into the model including age, education and occupation of the respondent, along with family income and access to healthcare. P value less than or equal to 0.05 was considered to be statistically significant with $95 \%$ confidence level.

\section{RESULTS}

The mean \pm SD age was $45.17 \pm 13.36$ years, and the majority $(69.25 \%)$ were females. The major two groups of the consumers' sample have basic education, with $27.25 \%$ who finished preparatory education, and a relatively smaller percentage $(25 \%)$ were graduated from secondary school. Overall, $67 \%$ of the sample resided in semiurban and slum areas. Urban residents formed $22.25 \%$ of the sample, whereas residents of rural areas represented $10.75 \%$. The highest percentage of the sample $(40.75 \%)$ claimed that their income was just sufficient to meet routine expenses, whereas $30.5 \%$ reported that they were in debt (Table 1 ). None of the studied sample was of high socioeconomic level, whereas $71.8 \%$ of the sample were classified as being of low level (Fig. 1).

Table 1: Sociodemographic characteristics of the studied sample of consumers of Alexandria Department of Health Education and Information services

\begin{tabular}{lc}
\hline Sociodemographic characteristics & $\mathrm{n}(\%)$ \\
\hline Age (years) & \\
Mean \pm SD & $45.17 \pm 13.36$ \\
$<30$ & $81(20.25)$ \\
$30-40$ & $58(14.50)$ \\
$40-50$ & $69(17.25)$ \\
$50-60$ & $133(33.25)$ \\
$60+$ & $59(14.75)$ \\
Sex & \\
Male & $123(30.75)$ \\
Female & $277(69.25)$ \\
Education & \\
Illiterate & $11(2.75)$ \\
Reads and writes & $47(11.75)$ \\
Primary & $56(14.0)$ \\
Preparatory & $109(27.25)$ \\
Secondary (general/technical) & $100(25.0)$
\end{tabular}


Occupation

Nonworking/housewife

Unskilled manual worker

Skilled manual worker/farmer

Residence

Urban

Semiurban/slum

Rural

Family income

Indebt

Just meet routine expenses

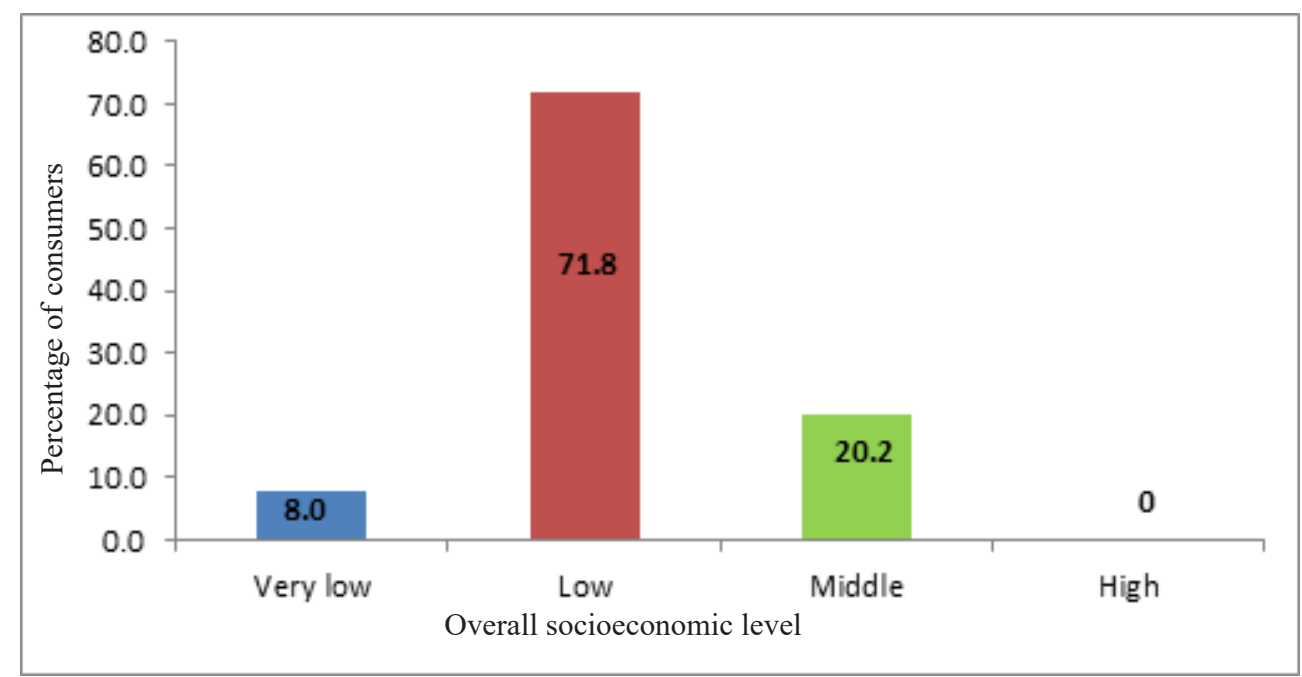

Fig. 1: Distribution of the studied sample of the consumers of Alexandria Department of Health Education and Information services according to their overall socioeconomic level.

Table 2 presents the distribution of the sample of consumers according to their responses to different items on the health literacy scale. Almost half of the studied sample $(49.7 \%)$ reported they sometimes needed help to read and understand written health materials. Right timely use of medicine for oneself and family members was said to be usually easy for $87.5 \%$ of the sample. Obtaining the required health information from credible sources was said to be usual for $37.7 \%$, whereas $40.7 \%$ admitted that they never understood the obtained health information with ease. Ease of communication with the health team on health issues got a 'never' response by $40.3 \%$ of the sample, whereas asking for assistance on confusing health matters was usually easy for $52.3 \%$. More than one-third of the sample (35.3\%) reported they could easily distinguish between accurate scientific health information and information disseminated for commercial purposes. The ability to apply such information in everyday life situations was said to be usual by $56.5 \%$. The overall mean \pm SD percent score of the sample's health literacy was $71.45 \pm 8.04$. Based on such responses and as shown in Fig. 2, the majority of the sample $(69.5 \%)$ had a fair health literacy level. The responses of only $7 \%$ of the sample reflected a high literacy level, whereas the remainder $(23.5 \%)$ showed a poor level of health literacy. 
Table 2: Responses to different items on the health literacy scale of the studied sample of consumers of Alexandria Department of Health Education and Information services

\begin{tabular}{|c|c|c|c|}
\hline The health literacy scale & Usually & Sometimes & Never \\
\hline $\begin{array}{l}\text { How often do you need to have someone help you when you read written material from your doctor or } \\
\text { pharmacy }^{\text {a }}\end{array}$ & 30.3 & 49.7 & 20.0 \\
\hline It is easy for me to take my medicine or give it to a family member in the right time in the right way & 87.5 & 11.3 & 1.2 \\
\hline It is easy for me to get the health information I need from trusted credible sources & 37.7 & 50.5 & 11.8 \\
\hline It is easy for me to understand the health information I get & 28.0 & 31.3 & 40.7 \\
\hline I can easily communicate with the health team to discuss my health issues & 19.7 & 40.0 & 40.3 \\
\hline I can easily ask for assistance to enquire about health matters I cannot understand & 52.3 & 35.7 & 12.0 \\
\hline $\begin{array}{l}\text { It is easy for me to distinguish between scientific/correct health information and other commercial } \\
\text { information }\end{array}$ & 35.3 & 41.7 & 23.0 \\
\hline I can handle and manage unexpected health problems & 39.5 & 38.7 & 21.8 \\
\hline I can share effectively in taking health decisions & 37.0 & 41.7 & 21.3 \\
\hline I can easily apply my health knowledge in everyday life situations & 56.5 & 33.3 & 10.2 \\
\hline
\end{tabular}

$\mathrm{N}=400$.

a: SILS, Single-Item Literacy Scale.

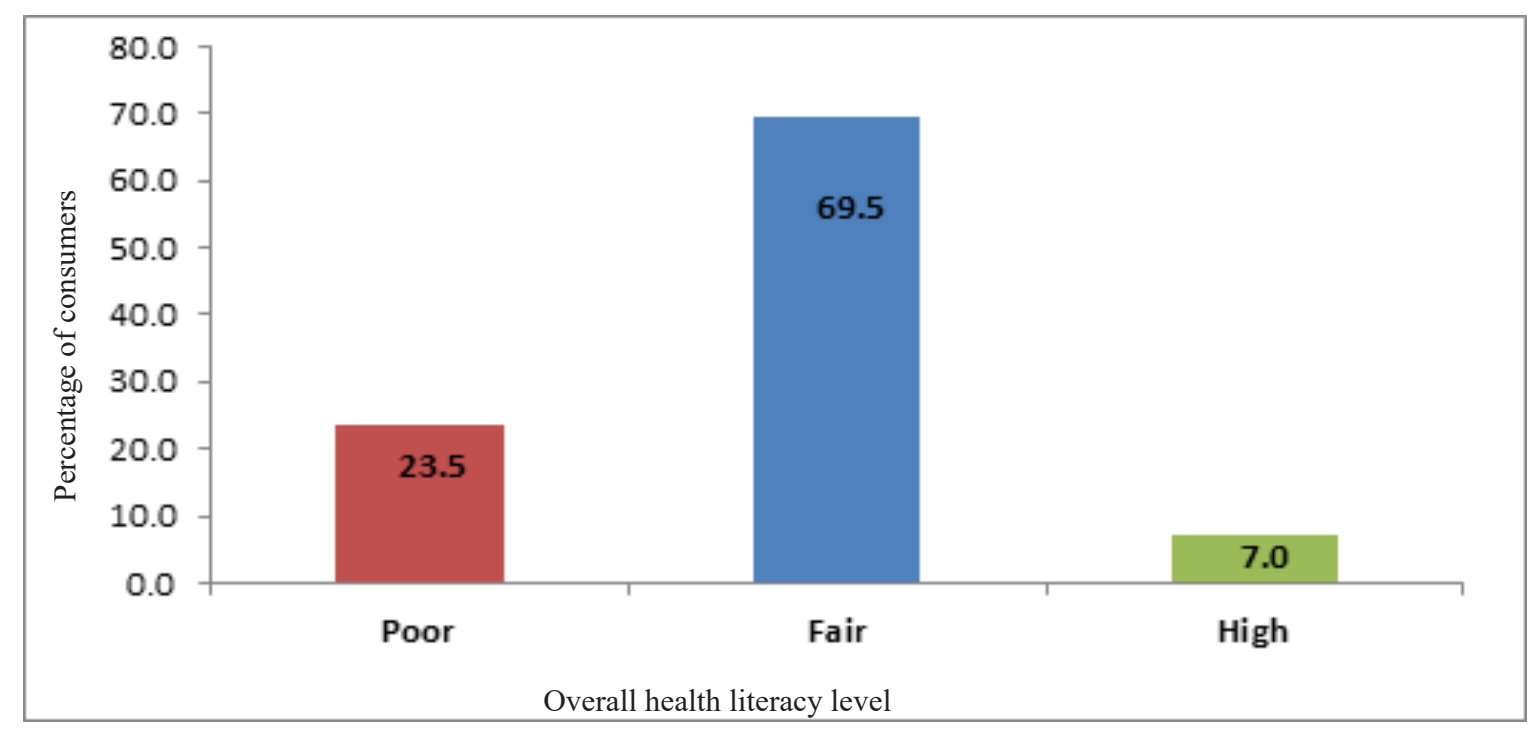

Fig. 2: Distribution of consumers of services of Alexandria Department of Health Education and Information (DHEI) according to their overall health literacy level

Figure 3 depicts the percent distribution of consumers according to their identified credible sources of health information. Physicians were the most frequently identified health information source, mentioned by $89.8 \%$, whereas nurses were selected by $30 \%$ of the sample. Health education sessions were chosen as a credible source of health knowledge by $58.8 \%$ of the consumers. Approximately one-fifth of the consumers' sample $(20.5 \%)$ credited their personal experience as a source of health knowledge and a fairly close percentage of $19.8 \%$ derived their knowledge from family and acquaintances. Health information gained at schools/college was only acknowledged by $2 \%$ of the sample. The role of social workers and health visitors as providers of credible health knowledge was denied by almost the entire sample, as they were chosen by only $0.5 \%$ of the sample as a source of health information. 


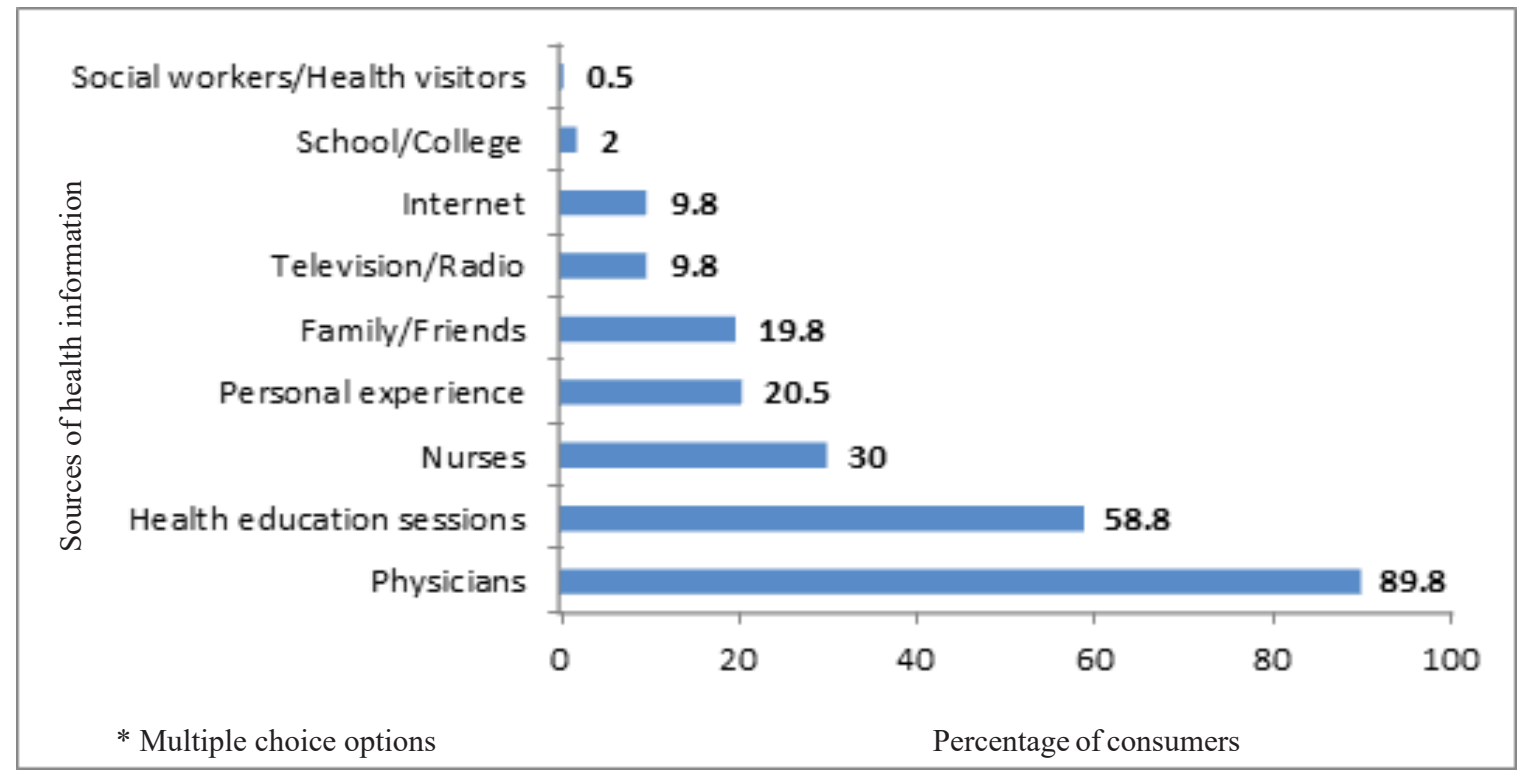

Fig. 3: Distribution of consumers of services of Alexandria Department of Health Education and Information (DHEI) according to their identified credible sources of health information

Consumers were equally distributed regarding their attitude towards health education services with a mean \pm SD percent score of $65.91 \pm 7.948$. Half of the consumers' sample demonstrated a neutral attitude, whereas the other half showed positive attitude toward health education as a service (Fig. 4). Nearly the entire sample agreed on the positive effect of health education services on health promotion and public health knowledge, whereas $83.5 \%$ agreed that health education services can help people have a better quality of life. Almost $84.3 \%$ of consumers agreed that health education services discuss issues that are relevant to their health priorities. Close percentages of the consumers' sample $(60.8 \%)$ believed health education is effective in modifying their health behaviors, and $74.8 \%$ believed health education is protecting their families' health. However, more than $70 \%$ of consumers agreed that the provided health education service helped solving their own or their families' health problems (Table 3).

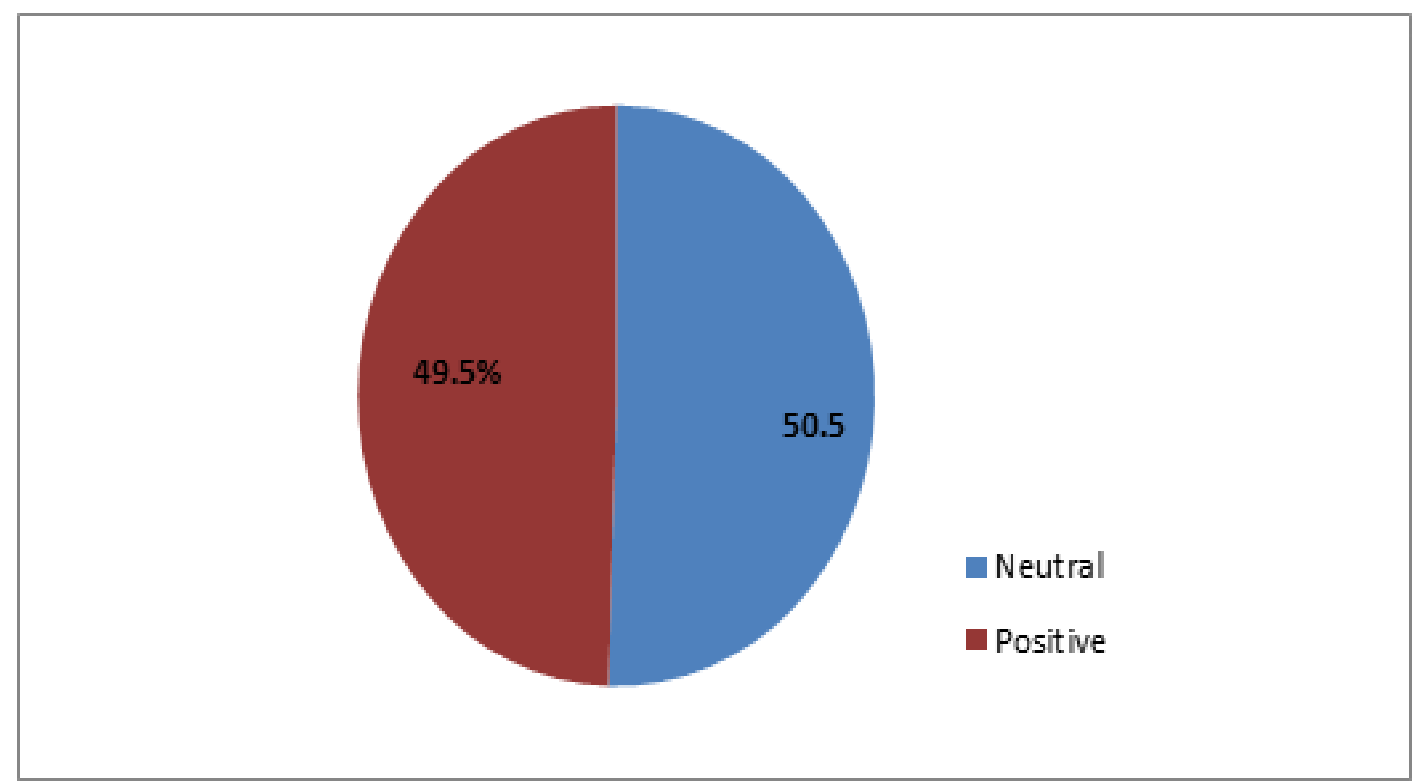

Fig. 4: Distribution of consumers of Alexandria Department of Health Education and Information (DHEI) services according to their overall attitude towards health education services 
Table 3: Responses to different attitude statements of the studied sample of consumers of Alexandria Department of Health Education and Information

\begin{tabular}{|c|c|c|c|}
\hline Attitude & Agree & Neutral & Disagree \\
\hline Health education activities discuss issues that are relevant for me and my health priorities & 84.3 & 5.7 & 10.0 \\
\hline Health education activities are ineffective in modifying my health behavior ${ }^{\mathrm{a}}$ & 19.4 & 19.8 & 60.8 \\
\hline Health education activities will help in protecting my own/family's health and preventing ill-health & 74.8 & 15.5 & 9.7 \\
\hline Health education activities do not help solving my own/family's health problem ${ }^{\text {a }}$ & 9.7 & 19.8 & 70.5 \\
\hline Health education is important for promoting my own/family's health & 99.3 & 0.7 & 0 \\
\hline It is useless to establish a specialized department exclusively to provide health education services ${ }^{\mathrm{a}}$ & 9.7 & 20.3 & 70.0 \\
\hline Health education service is useful in raising the public health knowledge & 97.3 & 0 & 2.7 \\
\hline Health education services help people have a better quality of life & 83.5 & 6.5 & 10.0 \\
\hline
\end{tabular}

$\mathrm{N}=400$.

a: Negative statement (reversed score).

Table 4 explains the percent distribution of the studied sample of consumers targeted by the Alexandria DHEI according to their satisfaction with different items of the service aspects. Approximately $82 \%$ of consumers were generally satisfied with the health education service. Approximately $90 \%$ of the sample were satisfied with the quality of the provided educational activities. Although $100 \%$ of the sample were satisfied with the effectiveness of the provided health education service in raising awareness, less than half of them (48.7\%) were satisfied with the effectiveness of the service in modifying behavior. The behavior and skills of the service providers obtained the highest mean \pm SD percent score (87.31 \pm 7.74$)$ among other aspects. The entire sample proclaimed their satisfaction with the providers' health communication skills, health knowledge, ability to attract attention, friendliness, respect, patience, acceptance, and nonjudgmental attitude. The various properties of the health message including concision, understandability, and updating met the satisfaction of around $90 \%$ of the sample. Even though the used educational methods were satisfactorily easy and clear for $79 \%$ of the sample, the variety, attractiveness, and sufficiency of the methods were not as satisfactory for consumers $(40,59.9$, and 69.2\%, respectively). The used place for providing the educational activities was satisfying as an educational setting for the whole sample. Approximately $90 \%$ of the sample was satisfied with the amenity features of the used setting such as ventilation, lighting, and seating. The sites where the DHEI activities are provided were satisfyingly accessible to $80.2 \%$, whereas the timing of the activities fitted the life routines of $60.2 \%$ of the sample. The least scored aspect of the provided health education service is the satisfaction with the provided educational materials with a mean \pm SD percent score of $51.44 \pm 16.27$. The sufficiency of the provided educational materials for the number of audience dissatisfied a majority of $80 \%$ which overshadowed their satisfaction with different criteria of the provided materials. Figure 5 clearly demonstrates that $90.2 \%$ had an overall high satisfaction level with the health education services provided by Alexandria DHEI. 
Table 4: Satisfaction with detailed items of the service aspects as reported by the studied sample of consumers of Alexandria Department of Health Education and Information

\begin{tabular}{|c|c|c|c|}
\hline Satisfaction with & Satisfied & Neutral & Dissatisfied \\
\hline \multicolumn{4}{|l|}{ Effectiveness and quality of the provided service } \\
\hline Overall quality of the educational activities & 90.2 & 9.8 & 0 \\
\hline Sufficiency of the educational activities & 70.2 & 20.0 & 9.8 \\
\hline Effectiveness of the service in changing attitudes and beliefs & 100 & 0 & 0 \\
\hline Effectiveness of the service in modifying behaviors & 48.7 & 30.8 & 20.5 \\
\hline Recipients' participation in planning and implementation & 31.0 & 19.5 & 49.5 \\
\hline Effectiveness of the educational activities in raising awareness & 100 & 0 & 0 \\
\hline \multicolumn{4}{|l|}{ Behavior and skills of the service providers } \\
\hline Skills of the staff in communicating health information & 100 & 0 & 0 \\
\hline Ability of the staff to modify behaviors & 59.7 & 30.5 & 9.8 \\
\hline Patience and acceptance of staff when handling audience questions & 69.7 & 30.3 & 0 \\
\hline Respect and friendliness of the staff towards audience & 100 & 0 & 0 \\
\hline Maintaining audience privacy and confidentiality & 60.7 & 39.3 & 0 \\
\hline Sufficiency of the staff health knowledge & 100 & & \\
\hline Ability of the staff to attract audience attention & 100 & & \\
\hline Staff's avoidance of judgment or discrimination against individuals & 100 & & \\
\hline \multicolumn{4}{|l|}{ Appropriateness of the used educational methods } \\
\hline Ease and clarity of the methods & 79.0 & 21.0 & 0 \\
\hline Methods' respect of the audience religious and social norms & 100 & 0 & 0 \\
\hline Use of audiovisual aids (AVAs) & 49.9 & 20.5 & 29.6 \\
\hline Sufficiency of the methods to cover the educational activity subject & 69.2 & 10.3 & 20.5 \\
\hline Variety of the methods used during the activity & 40.0 & 20.5 & 39.5 \\
\hline Appropriateness of the methods to audience learning level & 89.5 & 10.5 & 0 \\
\hline Attractiveness of the methods & 59.9 & 30.3 & 9.8 \\
\hline Cultural competence of the methods & 100 & 0 & 0 \\
\hline Concision and understandability of the health message & 89.5 & 10.5 & 0 \\
\hline Updating of the health message & 90.2 & 9.8 & 0 \\
\hline Suitability of the health message to the audience literacy level & 79.2 & 20.8 & 0 \\
\hline \multicolumn{4}{|l|}{ Quality of the provided educational materials } \\
\hline Sufficiency of the number of materials to cover all audience & 20.0 & 0 & 80.0 \\
\hline Effectiveness of the materials as a reminder of the health message & 20.4 & 20.8 & 58.8 \\
\hline Paper and printing quality of the materials & 30.2 & 20.8 & 49.0 \\
\hline \multicolumn{4}{|l|}{ Quality of the provided educational materials } \\
\hline Readability and understandability of the materials & 19.9 & 40.3 & 39.8 \\
\hline Attractiveness and outlook of the materials & 19.9 & 40.3 & 39.8 \\
\hline
\end{tabular}


Relevance of the materials' topics to audience

Presence of answers to most health queries in the materials

Ease of access to DHEI services

Ease of knowing time, subject, and place of upcoming activities

Ease of accessibility and reach to the sites where activities are held

Suitability of the activities' schedule with audience life routines

Convenience of the used place as an educational setting

Ventilation and lighting of the educational setting

Sufficiency of seating for all audience in the educational setting

Suitability of the used place as a learning conducive setting

Overall service provided by the DHEI

General satisfaction with the health education service provided

$\mathrm{N}=400$.

DHEI, Department of Health Education and Information

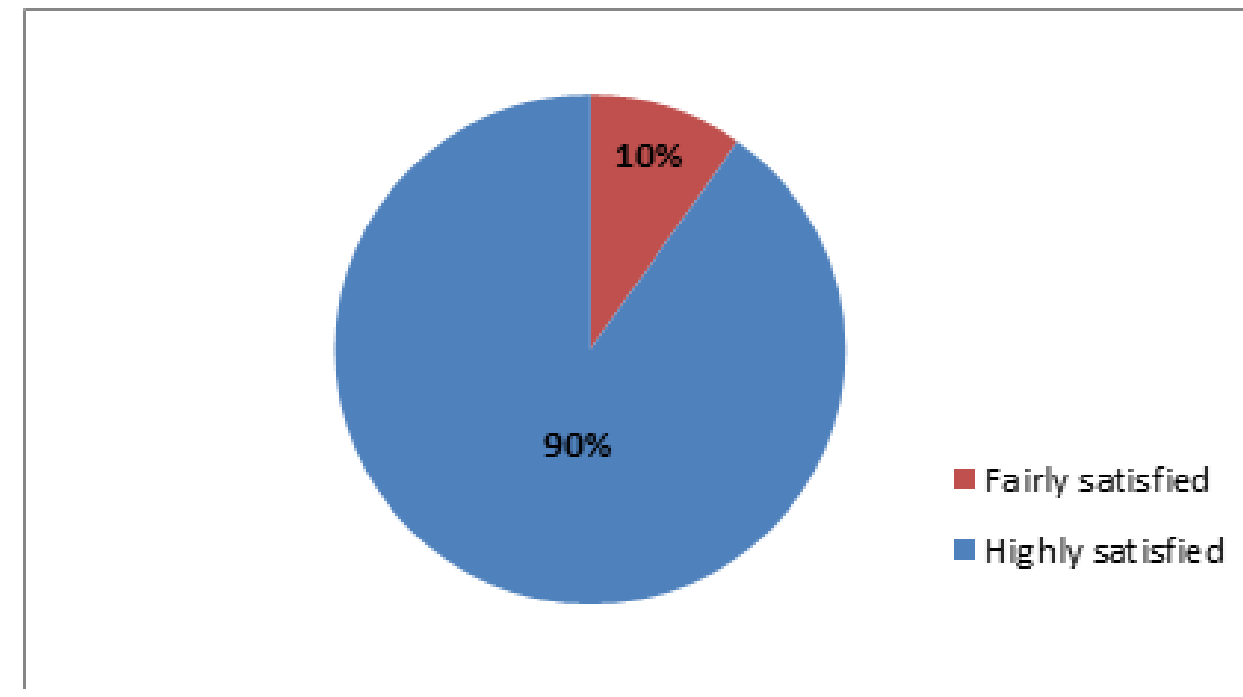

Fig. 5: Distribution of consumers of services of the Alexandria Department of Health Education and Information (DHEI) according to their overall satisfaction level

Multiple linear regression summarized in Table 5 showed a significant influence of a number of socioeconomic characteristics on consumers' overall satisfaction with the provided health education services. Respondent's education and affording access to paid healthcare had a positive significant influence on overall satisfaction with the provided services $(P<0.01)$. On the contrary, occupational level of consumers and level of family income negatively influenced their overall satisfaction $(P<0.01)$. 
Table 5: Summary of stepwise multiple regression models for consumers' satisfaction by their socioeconomic characteristics

\begin{tabular}{|c|c|c|c|c|c|}
\hline \multicolumn{3}{|c|}{ Unstandardized coefficients } & \multicolumn{3}{|c|}{ Standardized coefficients } \\
\hline Model & $\mathrm{B}$ & Standard error & $\beta$ & $\mathrm{t}$ & Significant \\
\hline Constant & 83.077 & 2.792 & & 29.756 & 0.000 \\
\hline Age & -0.047 & 0.045 & -0.094 & -1.031 & 0.303 \\
\hline Education & 0.582 & 0.172 & 0.307 & 3.391 & 0.001 \\
\hline Occupation & -3.978 & 0.568 & -0.862 & -7.004 & 0.000 \\
\hline Healthcare affordability & 0.096 & 0.023 & 0.191 & 4.083 & 0.000 \\
\hline Family income & -3.660 & 0.439 & -0.425 & -8.344 & 0.000 \\
\hline
\end{tabular}

$\mathrm{r} 2=0.375$.

\section{DISCUSSION}

Most Alexandria DHEI consumers acknowledged the role of health education in raising public health knowledge, promoting health, and helping people to have a better quality of life. This study highlighted the level of satisfaction of the department consumers with different aspects of the department services, which may be used for monitoring the health education services and updating policies to improve the quality of these services.

Overall, $90 \%$ of the DHEI consumers were highly satisfied with the provided health education services. Evaluating consumers' satisfaction with health education has frequently been a part of evaluating the provided health care services over all. A study performed in Jimma University Hospital, Ethiopia (2011) showed that a lower percentage of consumers (64\%) were satisfied by health education provision at the hospital in comparison with the current study ${ }^{[16]}$. In Muscat, a study was performed to assess consumers' satisfaction with primary health care (PHCs) in the Omani capital. Totally, $81 \%$ of participants were satisfied by the received services. In concordance with the present study, the social skills of the staff received the highest mean percent score compared with other aspects of the provided service. The provision of health education materials was in no better condition at Muscat PHCs than it was at Alexandria DHEI $^{[17]}$. In Riyadh, health education services offered at PHCs were specifically studied from consumers' point of view. In contrary to the present study, the higher majority of the Saudi sample reported receiving printed health education materials at some point of their visit at the PHC, which were also highly satisfying to the majority of the sample. However, a lower percentage of the Saudi participants were highly satisfied with the overall health education services provided at Riyadh PHCs compared with highly satisfied consumers of Alexandria DHEI services ${ }^{[18]}$. Materials are undeniably pricey, in terms of designing expertise and printing costs. Facing other priorities with a limited budget for different health services, materials are commonly sacrificed.

The entire sample perceived the provided service as satisfyingly effective in raising awareness and modifying beliefs and attitudes. However, the decreased consumers' satisfaction with the effectiveness of these activities in changing behaviors as well as the lack of participation in activity planning and implementation reduced the total consumers' satisfaction with the quality and effectiveness of the service.

Ease of access including the convenience of the place, its location, and amenities appeared more satisfying to a majority of consumers than did the timing of the activities. High satisfaction reported by the DHEI regarding service accessibility was in concordance with the results of a study performed in North India, to assess patients' satisfaction toward the services received at rural health centers. Accessibility in terms of proximity to homes was the most cited reason by Indian participants for seeking services at these centers. The pleasant attitude of the staff was prioritized to the skills of the doctors at these centers ${ }^{[19]}$. Probably, most PHCs enjoy the advantage of proximity and ease of reach to residents of their catchment areas. Health education services offered during waiting times or as an extension of the originally sought health service are mostly convenient for target audience, especially if the received health message is relevant and the provided health service is timely and of good quality. Thereby, different services, including health education, offered at peripheral health units are usually satisfactorily accessible to their beneficiaries. It also appears that the first-line staff such as health educators, nurses, and PHC staff tend to develop their social and communication skills, even if they pay less attention to raising their technical competencies. Notably, healthcare staff is commonly a trusted source of health knowledge for different population segments. Therefore, the staff carrying on the responsibility of health education must bear the continuous burden of updating their health knowledge and teaching skills to effectively fulfill their trusted role in the community. 
Physicians were typically regarded as a credible source of health knowledge by almost $90 \%$ of the consumers' sample. Oppositely, nurses were identified as an information source by less than one-third of the sample. This was rather unexpected, as nurses commonly have more frequent contact with consumers and are more likely to carry on health education activities. Besides, for a sample with a majority having fair to poor abilities to communicate with the health team, nurses are more plausible candidates for health communication. The nurses' work overload might definitely interfere with their health education tasks. However, it is the negligible recognition of social workers and health visitors that poses a challenge to the DHEI, considering that social workers and health visitors constitute a considerable percentage of the DHEI staff.

Exploring the influence of various socioeconomic determinants on consumers' satisfaction with the provided DHEI services in the present study showed a positive significant effect of consumers' education and a negative effect of their income level on their overall level of satisfaction. The negative influence of income on consumers' satisfaction was similarly proved by a study evaluating factors influencing patient satisfaction in Iran in 2014. However, education also proved to have a negative influence on satisfaction in opposition to the findings of the present study ${ }^{[20]}$.

Seemingly, the health education service provided by Alexandria DHEI has successfully achieved an overall satisfactory outcome with respect to its target beneficiaries. Still, it is noteworthy that the prevalence of the lower socioeconomic standard among the consumers' sample could have had a considerable share in their relatively high satisfaction. Seeking a facility like health care or NGOs for a certain purpose and receiving an extra unpaid service such as health education might seem like a bonus for lower socioeconomic classes. Being handled courteously and given the impression that their health awareness is valued can be highly satisfying for the majority for such population group no matter what the outcome is on their final health behavior and quality of life. This may have shifted the consumers' evaluation of the service itself to their evaluation of their relationship with the provider.

\section{LIMITATIONS OF STUDY}

The study was carried out entirely in governmental health facilities and community organizations where the DHEI provides its services. Thereby, the sample was biased toward consumers of lower socioeconomic standard, who are mostly residents of slum and semiurban areas served by such facilities. The DHEI usually holds its activities in the morning when men are usually at work, which also biased the sample toward a female majority. Limitations owing to the interview questionnaire included the relative difficulty to respond to five-Likert scales especially by a sample mostly of low education, besides the inherent bias of interviews in terms of social desirability.

\section{CONCLUSION}

The Department of Health Education and Information in Alexandria provides an overall satisfactory service for its consumers. The Department makes good use of the settings in which it serves its consumers and the staff is skilled at establishing rapport with their audience. However, consumers were not as satisfied with the technical aspects of the service including teaching methods and the ability of the staff to effect an actual behavior change. Health education materials provided by the department are markedly deficient. However, with the health literacy and educational level of the majority of the department's audience, increasing the availability of handouts can help in sustaining the health messages and provide more clues that trigger behavior change. It is also recommended that the department has to enhance the technical skills of its staff through training on health education methods and behavior modification techniques. Advocating for the credibility of social workers and health visitors as health educators among the community is a strenuous task that should be planned for by the department. Different socioeconomic features proved to influence consumers' satisfaction with health education services. Although these features cannot be modified by the department, health education staff is compelled to learn how to tailor their teaching methods and health messages to fit the audience educational, occupational, and economic needs.

\section{CONFLICT OF INTEREST}

There are no conflicts of interest

\section{REFERENCES}

1. Leone R, Walker C, Curry L, Agee EJ. Application of a marketing concept to patient-centered care: coproducing health with heart failure patients. Online J Issues Nurs 2012; 17:7-8.

2. Smith WA. Social marketing: an overview of approach and effects. Inj Prev 2006; 12:38-43.

3. Wen J, Schulman K. Can team-based care improve patient satisfaction? a systematic review of randomized controlled trials. PLoS One 2014; 9:e100603.

4. Chow A, Mayer E, Darzi A, Athanasiou T. Patientreported outcome measures: the importance of patient satisfaction in surgery. Surgery 2009; 149:435-443.

5. Faber M, Bosch M, Wollersheim H, Leatherman S, Grol R. Public reporting in health care: How do consumers use quality-of-care information? a systematic review. Med Care 2009; 47:3-8.

6. Applebaum R, Straker J, Geron S. Assessing satisfaction in health and long term care: practical 
approaches to hearing the voices of consumers. New York, NY: Springer Publishing Company; 2000. pp. 3-27.

7. Braunsberger K, Gates RH. Patient/enrollee satisfaction with healthcare and health plan. J Consum Mark 2002; 19: 575-590.

8. Tateke T, Woldie M, Ololo S. Determinants of patient satisfaction with outpatient health services at public and private hospitals in Addis Ababa, Ethiopia. Afr J Prim Health Care Fam Med 2012; 4: 384-395.

9. Al-Abri R, Al-Balushi A. Patient satisfaction survey as a tool towards quality improvement. Oman Med J 2014; 29: 3-7.

10. Task Force on Community Preventive Services. The social environment. In: Zara S, Briss $\mathrm{P}$, Harris $\mathrm{K}$, editors. The guide to community preventive services: what works to promote health. New York, NY: Oxford University Press; 2005. pp. 114-141.

11. El-Gilany A, El-Wehady A, El-Wasify M. Updating and validation of the socioeconomic status scale for health research in Egypt. East Mediterr Health J 2012; 18: 962-968.

12. Morris NS, MacLean C, Chew L, Littenberg B. The Single Item Literacy Screener: evaluation of a brief instrument to identify limited reading ability. BMC Fam Pract 2006; 7: 21-24.

13. Cameron KA, Ross EL, Clayman ML, Bergeron AR, Federman AD, Bailey SC. Measuring patients' self-efficacy in understanding and using prescription medication. Patient Educ Couns 2010; 80: 372-376.

14. Tung YC, Chang GM. Patient satisfaction with and recommendation of a primary care provider: associations of perceived quality and patient education. Int J Qual Health Care 2009; 21: 206-213.

15. Chin LY, Amir L. Survey of patient satisfaction with the Breastfeeding Education and Support Services of the Royal Women's Hospital, Melbourne. BMC Health Serv Res 2008; 8: 83-93.

16. Assefa F, Mosse A, Hailemichael Y. Assessment of Clients' Satisfaction with Health Service Deliveries at Jimma University Specialized Hospital. Ethiop J Health Sci 2011; 21: 101-109.

17. Albalushi RM, Sohrabi MR, Kolahi A. Clients' satisfaction with Primary Health Care in Muscat. Int J Prev Med 2012; 3: 713-717.

18. Asiri N, Jradi H, Bawazir AA. Patients' satisfaction with health education services at Primary Health Care centers in Riyadh, KSA. J Community Med Health Educ 2013; 4: 268-273.

19. Galhotra A, Sarpal SS, Gupta S, Goel NK. A crosssectional study on patient satisfaction toward services received at rural health center, Chandigarh, North India. Ann Trop Med Public Health 2013; 6: 240-244.

20. Kelarijani SEJ, Jamshidi R, Heidarian AR, Khorshidi M. Evaluation of factors influencing patient satisfaction in social security hospitals in Mazandaran province, North of Iran. Caspian J Intern Med 2014; 5: 232-234. 